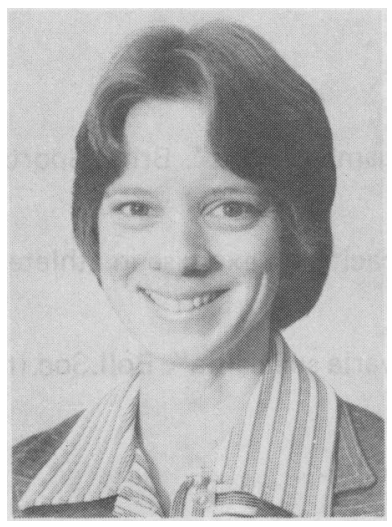

\section{EFFECT OF PHYSICAL CONDITIONING ON BLOOD LACTATE DISAPPEARANCE AFTER SUPRAMAXIMAL EXERCISE}

\author{
Blanche W. EVANS, EdD and K. J. CURETON, PhD \\ Human Performance Laboratory, \\ University of Georgia, Athens, GA 30602, USA
}

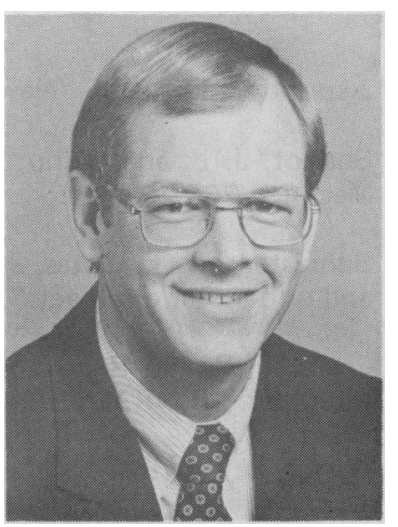

\title{
ABSTRACT
}

The purpose of this study was to investigate the effect of physical conditioning on the rate of blood lactate disappearance during recovery from supramaximal exercise. The rate of blood lactate disappearance was determined in 11 female and 4 male subjects before and after a 6-week conditioning programme. Blood samples were taken during the 30 minutes following supramaximal exercise during both passive (resting) and active recoveries. Pre-test active recovery was performed at $25 \% \mathrm{VO}_{2}$ max; post-test active recovery was performed at both the same absolute and relative intensities $\left(\% \mathrm{VO}_{2} \max \right)$ as during the pre-test. Eight of the subjects trained 4 days/week for 6 weeks with high-intensity interval bicycle ergometer exercise, and 7 subjects served as controls. The conditioning programme significantly $(p<.05)$ increased $\mathrm{VO}_{2}$ max by $6.7 \mathrm{ml} / \mathrm{kg} . \mathrm{min}(15 \%)$ and work capacity on the cycle ergometer by 2.8 minutes (27\%). Physical conditioning did not affect significantly $(p>.05)$ the rate of blood lactate disappearance measured during passive recovery or during active recovery at the same absolute intensity, but increased significantly $(p<.05)$ the rate of blood lactate disappearance during active recovery performed at the same relative exercise intensity. The increased disappearance rate following conditioning was attributed to the higher absolute intensity of recovery work performed.

Key Words: Active and passive recovery, Blood lactate, Metabolism, Physical training.

\section{INTRODUCTION}

During resting recovery from strenuous exercise, the disappearance of blood lactate is known to be a logarithmic function of time with a half-time of approximately 15 minutes (Margaria et al, 1933; Newman et al, 1937). The rate of blood lactate disappearance is increased if light aerobic exercise is performed during the recovery period (Belcastro and Bonen, 1975; Bonen and Belcastro, 1976; Davies et al, 1970; Gisolfi et al, 1966; Hermansen and Stensvold, 1972; Newman et al, 1937; Rammal and Strom, 1949; Stamford et al, 1978; Stamford et al, 1981; Weltman et al, 1977; Weltman et al, 1979). The rate of blood lactate disappearance is related to the intensity of the recovery exercise with optimal removal occurring between approximately

Address correspondence to:

Dr. Blanche Evans,

Coleman Gymnasium,

University of North Carolina at Greensboro,

Greensboro,

NC 27412, USA
$25 \%$ and $65 \%$ of $\mathrm{VO}_{2}$ max for bicycle ergometer and treadmill exercise (Belcastro and Bonen, 1975; Davies et al, 1970; Hermansen and Stensvold, 1972).

A number of investigators have suggested that differences among individuals in the rate of blood lactate disappearance during active recovery may be related to their level of physical condition. Strom (1949) noticed that blood lactate disappearance following strenuous exercise increased as recovery exercise intensity was increased up to a certain intensity, which was higher in well-trained subjects than in untrained subjects. Gisolfi, et al (1966) found a higher rate of blood lactate disappearance following a bout of exhaustive treadmill running in a distance runner than by a sprinter, and hypothesised that the greater lactate disappearance by the distance runner may have been due to his higher level of physical condition and to his ability to carry out a higher rate of recovery work. Davies et al (1970) reported a considerably greater rate of blood lactate disappearance following a heavy bout of cycle ergometer exercise in one subject with a high $\mathrm{VO}_{2}$ max compared with three other subjects who had much lower $\mathrm{VO}_{2}$ 
max values. These researchers hypothesised that the difference was due to the fitness level of the subjects. In comparing two of their studies, Bonen and Belcastro (1976) noted that rates of blood lactate disappearance during active recovery from strenuous exercise, performed at similar intensities, were significantly higher in a study having trained subjects compared with the other study in which subjects were less well-trained.

Although the studies cited above have suggested that the level of physical condition may influence the rate of blood lactate disappearance, no previous investigation has directly studied this problem. Therefore, the purpose of this study was to investigate the effect of physical conditioning on the rate of blood lactate disappearance during active and passive recovery from strenuous exercise.

\section{METHODS}

Subjects. The subjects were 11 women and 4 men enrolled at the University of Georgia. Most were graduate students in physical education who were in moderately good physical condition. The mean ( \pm SD) physical characteristics for the men and women, respectively, were: age, o $27.3 \pm 3.2$ and $\$ 27.4 \pm 3.4$ years; height, of $182.9 \pm 5.4$ and $q 166.7 \pm 4.9 \mathrm{~cm}$; and weight, $\delta 74.8 \pm 3.4$ and $\$ 58.6 \pm 8.6 \mathrm{~kg}$. All subjects were given a detailed description of the experiment and procedures to be used and gave written informed consent.

Research design. Subjects were assigned randomly to either a control or exercise group. The control group consisted of six women and one man and the exercise group consisted of five women and three men. Subjects in the exercise group trained four days/week for six weeks on a Monark cycle ergometer. Workouts included six exercise bouts of four minutes duration, using a work rate estimated to elicit $85 \% \mathrm{VO}_{2}$ max. Each week $\mathrm{VO}_{2}$ max was reassessed and utilised to adjust the exercise intensity to account for increases in aerobic capacity. The control group did not engage in any systematic endurance training during this time. Maximal oxygen uptake, physical work capacity, and the rate of blood lactate disappearance during passive and active recovery from strenuous exercise were assessed in all subjects prior to and immediately following the conditioning programme.

Work capacity test. A continuous, load-incremented cycle ergometer test was utilised to assess maximal oxygen uptake and physical work capacity. The test began with a work rate of 60 watts for women and 120 watts for men. After each 2-minute interval, the work rate was increased by 30 watts. Pedal rate was maintained at $60 \mathrm{rev} / \mathrm{min}$ throughout the test. The subject continued until exhausted as determined by the inability to maintain the pedal rate. The criteria for attaining
$\mathrm{VO}_{2}$ max was an increase in $\mathrm{VO}_{2}$ of less than 150 $\mathrm{ml} / \mathrm{min}$ between workloads, or a blood lactate concentration greater than $10 \mathrm{mmol} / \mathrm{l}$ and an $R>1.1$. The duration of the test was used as a measure of physical work capacity.

Metabolic measurements were made every $\mathbf{3 0}$ seconds during the test using the semi-automated system described by Wilmore and Costill (1974). The volume of expired air was measured using a Parkinson-Cowan CD-4 dry gas meter. Percentages of oxygen and carbon dioxide in the expired gas were determined using Beckman OM-11 and LB-2 electronic gas analysers, calibrated prior to each test with gases previously analysed using the Lloyd-Gallenkamp apparatus. Heart rate was determined from electrocardiogram recordings obtained during the last 10 seconds of each minute of the test. A blood sample was taken 3 minutes after the test for blood lactate determination.

Blood lactate disappearance. To determine the rate of blood lactate disappearance, subjects performed a supramaximal bout of cycle ergometer exercise. Subjects pedalled until exhaustion at $70 \mathrm{rev} / \mathrm{min}$ at a load estimated to elicit $110 \%$ of $\mathrm{VO}_{2}$ max. For 30 minutes following the exercise at the pre-test, subjects either sat in a chair (passive recovery) or continued to work at $25 \%$ of $\mathrm{VO}_{2}$ max (active recovery). At the post-test, subjects performed passive recovery and two active recovery conditions consisting of work at $25 \%$ of pre-test $\mathrm{VO}_{2} \max$ (same absolute work rate) and $25 \%$ post-test $\mathrm{VO}_{2} \max$ (same relative work rate). The $25 \%$ $\mathrm{VO}_{2}$ max intensity was utilised for active recovery because it is at the low end of the range of intensities identified previously as optimal for promoting lactate disappearance during bicycle exercise (Belcastro and Bonen, 1975; Davies et al, 1970) and unlikely to result in an elevation in baseline blood lactate levels that would affect the rate of blood lactate disappearance (Stamford et al, 1981).

Blood samples were taken from a prewarmed fingertip at 3, 8, 15, 20 and 30 minutes after the supramaximal exercise. Concentrations of lactate were measured in triplicate using the Strom (1949) modification of the Barker and Summerson (1941) procedure. Logarithmic transformations (base 10) of values at $8,15,20$ and 30 minutes were used to determine rate of blood lactate disappearance.

Statistical analysis. A two-way (group $x$ recovery condition) ANOVA with repeated measurements on one factor (recovery condition) was used to test the significance of differences between the control and exercise group changes over the treatment period for the physiological variables. A significant group $x$ test interaction indicated changes in the control and conditioning groups from pre-test to post-test were significantly different. 

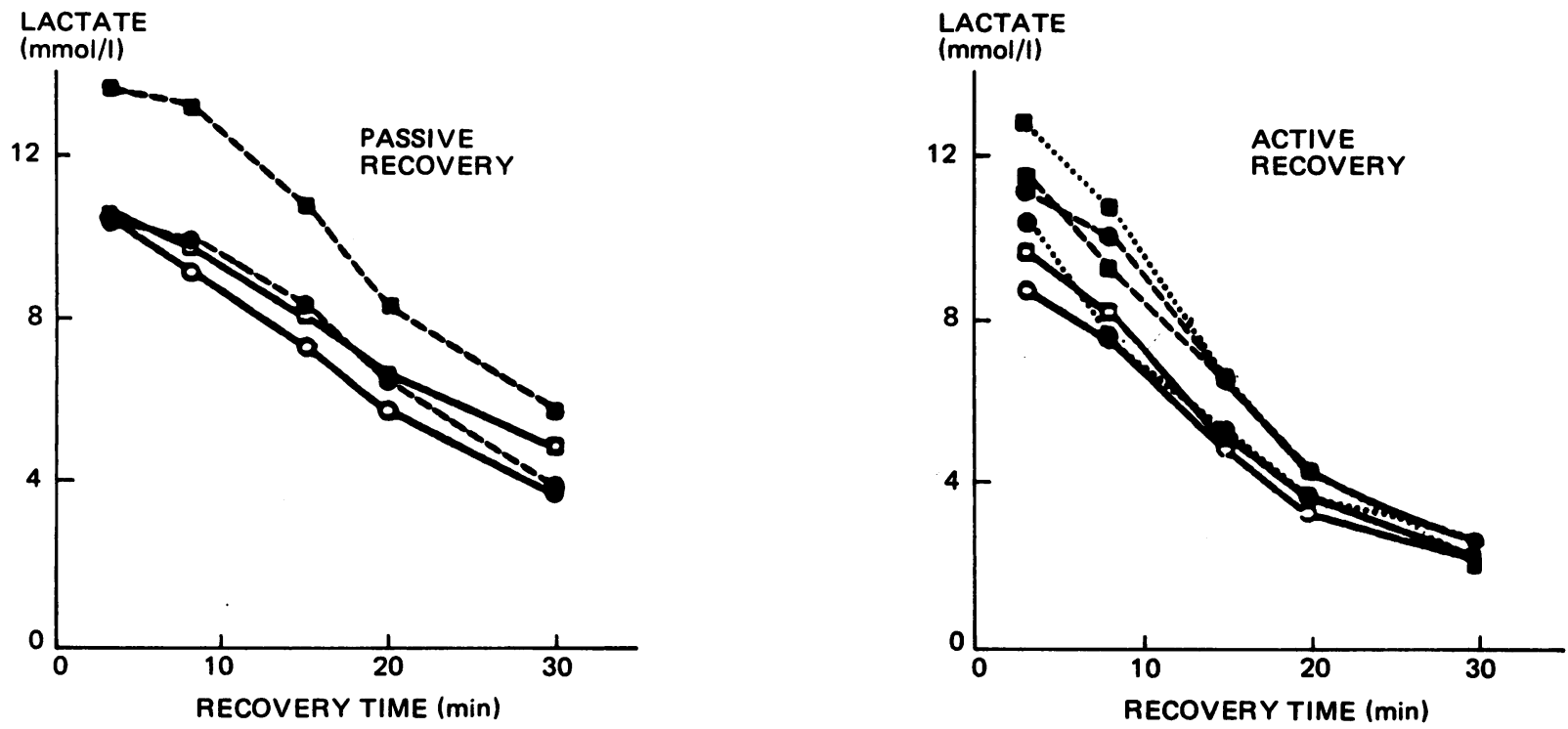

Fig. 1: Relationship of mean blood lactate to time during recovery. Passive Recovery Symbol Key: O _ control group pre-test; control group post-test; exercise group pre-test; $1 . .$. exercise group post-test.

Active Recovery Symbol Key: O - control group pre-test; ..... control group post-test with recovery at the same absolute work rate; $\bullet . .$. control group post-test with recovery at the same relative work intensity; $\square-$

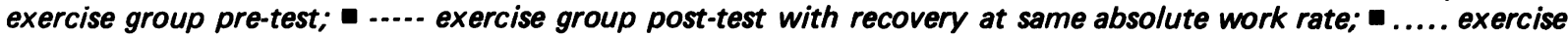
group post-test with recovery at the same relative intensity.
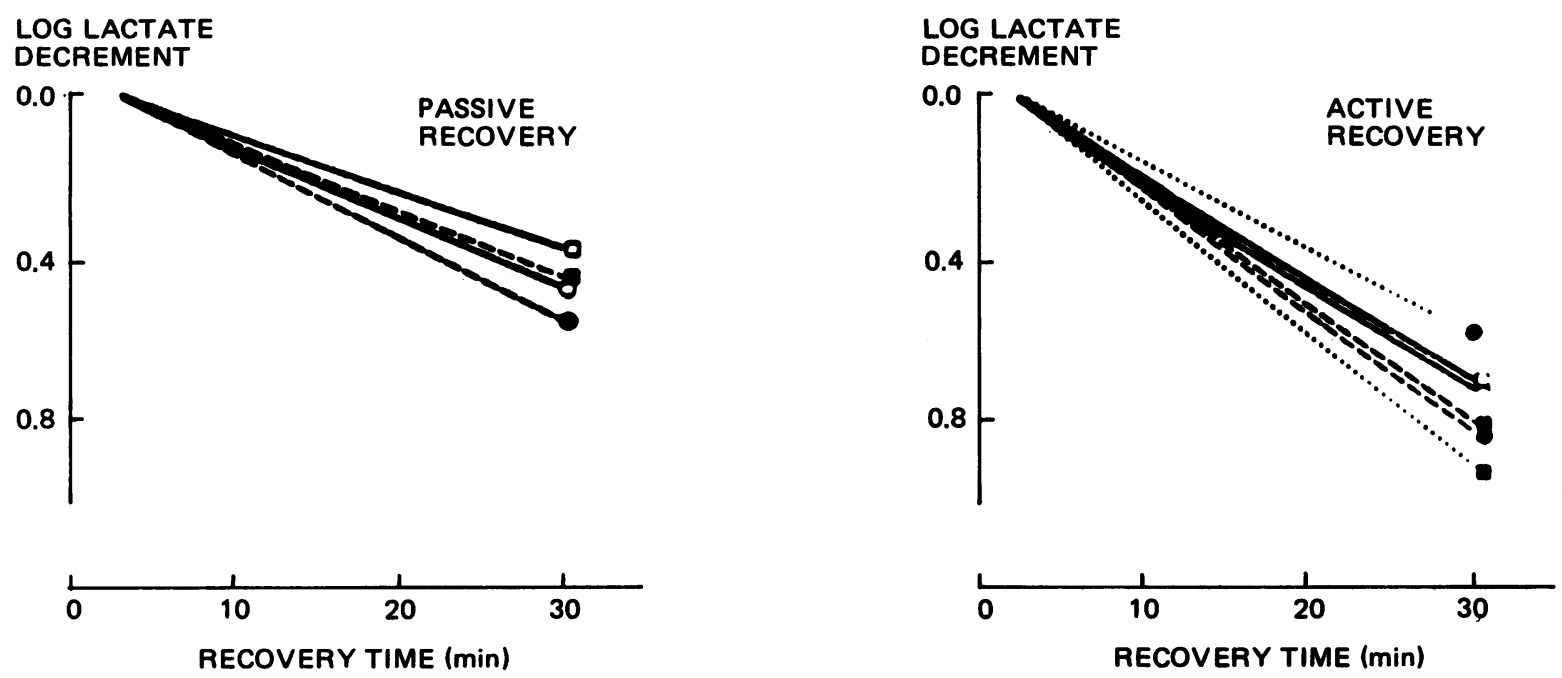

Fig. 2: Relationship of the mean decrement in $\log _{10}$ blood lactate (mmol/I) to time during recovery. The slope of the lines is equal to the rate of blood lactate disappearance. The lines are brought to a common origin to facilitate comparison of slopes. Symbols are the same as in Figure 1. 
A ' $t$ ' test for dependent groups was then used to test for simple main effects. An alpha of .05 was used for all significance tests.

\section{RESULTS}

The conditioning programme produced a substantial training effect evidenced by changes in $\mathrm{VO}_{2} \max$ and work capacity. Mean increases in $\mathrm{VO}_{2} \max$ in $1 / \mathrm{min}$ $(13.6 \%), \mathrm{VO}_{2} \max$ in $\mathrm{ml} / \mathrm{kg} \cdot \min (15.1 \%)$ and ride time (25.9\%) were substantial in the exercise group, whereas only minor changes occurred in the control group. Changes in $\mathrm{VO}_{2} \max (\mathrm{ml} / \mathrm{kg} . \mathrm{min})$ and ride time in the exercise group were significantly $(p<.05)$ greater than those in the control group.

The mean blood lactate concentrations and disappearance rates during the 30 -minute recovery period following the supramaximal exercise are presented in Figures 1 and 2, respectively. Pre- to post-test changes in the rate of blood lactate disappearance during passive recovery were not significantly $(p>.05)$ different in the exercise and control groups. Although the disappearance rate was somewhat faster in the exercise group following conditioning, a similar small change was obtained for the control group (Fig. 2). Blood lactate at the onset of recovery was substantially higher in the exercise group following conditioning than in the control group, and it remained higher throughout recovery (Fig. 1).

Pre- to post-test changes in the rate of blood lactate disappearance were also not significantly $(p>.05)$ different in the exercise and control groups during recovery performed at the same absolute work rate. Both groups had faster disappearance rates at the posttest (Fig. 2) that were associated with higher blood lactate concentrations at the onset of recovery (Fig. 1).

In contrast, the rate of blood lactate disappearance measured during active recovery at the same relative intensity $\left(\% \mathrm{VO}_{2} \quad \max \right)$ was significantly $(\mathrm{p}<.05)$ greater following conditioning than before conditioning in the exercise group, but not significantly $(p>.05)$ changed for the control group (Fig. 2). The faster disappearance rate following conditioning in the exercise group may have been due, at least in part, to the higher blood lactate concentration at the onset of recovery, since blood lactate concentrations after $\mathbf{3 0}$ minutes of recovery were similar (Fig. 1).

\section{DISCUSSION}

As in previous research (Belcastro and Bonen, 1975; Bonen and Belcastro, 1976; Davies et al, 1970; Gisolfi et al, 1966; Hermansen and Stensvold, 1972; Newman et al, 1937; Rammal and Strom 1949; Stamford et al, 1978; Stamford et al, 1981; Weltman et al, 1977; Weltman et al, 1979), blood lactate disappeared from the blood more rapidly during active than resting recovery. The increased rate of blood lactate disappearance during active recovery is thought to be due to the increased use of lactate for fuel through oxidative metabolism by the active skeletal muscles and to increased blood flow and transport of lactate from the active muscles to other organs removing it from the blood, such as the inactive skeletal muscles, heart and liver (Bonen and Belcastro, 1976; Gisolfi et al, 1966; Hermansen and Stensvold, 1972; Stamford et al, 1981).

Physical conditioning did not significantly affect the rate of disappearance of lactate from the blood during passive recovery or during active recovery performed before and after conditioning at the same absolute work rate. The finding for passive recovery is consistent with previous studies that have reported no difference between individuals with high and low work capacity in the rate of disappearance of lactate from the blood during passive recovery (Gisolfi et al, 1966; Johnson and Brouha, 1942). No comparable empirical data is available relating fitness level to the rate of blood lactate disappearance during active recovery performed at a standard work rate.

Theoretically, one might expect the rate of blood lactate disappearance under both of these recovery conditions to be higher in the trained compared with the untrained state for several reasons. First, as observed in this study, the blood lactate concentration following maximal-effort supramaximal exercise is often higher following conditioning (Robinson and Harmon, 1942). This adaptation in itself may increase the rate of blood lactate disappearance since the recovery curve for lactate is exponential with the absolute amount of lactate removed being a function of the amount present at any given time. Hermansen and Stensvold (1972), however, have suggested that blood lactate disappearance may not be a function of blood lactate concentration when concentrations exceed 40 to $50 \mathrm{mg} \%$.

Second, sṫrenuous physical conditioning increases the oxidative capacity of the trained skeletal muscles which, theoretically, could increase the use of lactate for fuel in a manner analogous to that observed for fatty acids (Holloszy et al, 1977), thereby increasing the extraction of lactate from the blood. A positive correlation has been reported between the rate of blood lactate disappearance and percentage of slow twitch skeletal muscle fibres (Bonen et al, 1978), lending support to this reasoning.

Third, the distribution of blood flow during submaximal exercise is altered. Following conditioning, blood flow to the splanchnic region is increased during submaximal exercise, whereas blood flow through active skeletal muscles remains the same or is decreased slightly (Clausen and Trap-Jensen, 1970; Varnauskas et al, 
1970). These alterations in blood flow distribution might be expected to increase the rate of blood lactate disappearance during active recovery.

Finally, physical conditioning decreases the concentration of blood lactate observed at any given submaximal work intensity and $\% \mathrm{VO}_{2}$ max (Gollnick and Hermansen, 1973; Robinson and Harmon, 1941) and increases the anaerobic threshold (Davis et al, 1979; Williams et al, 1967). These adaptations should decrease the baseline blood lactate level during recovery. In the present study, the intensities of the active recoveries were low, however, and baseline blood lactate elevation should have been insignificant.

The rate of blood lactate disappearance was increased following conditioning when measured at the same relative intensity $\left(\% \mathrm{VO}_{2} \mathrm{max}\right)$. This finding, coupled with the absence of a changed lactate disappearance rate during resting recovery and active recovery at a standard work rate, strongly suggests the increased disappearance rate was a function of recovery work and $\mathrm{VO}_{2}$. The average increase in the absolute rate of recovery work performed following conditioning was relatively small, however, 8.5 watts, and would be expected to increase the recovery $\mathrm{VO}_{2}$ by only an average of about $0.10 \mathrm{I} / \mathrm{min}$.

Unfortunately, we cannot conclude that the increased lactate disappearance rate observed during recovery at $25 \% \mathrm{VO}_{2}$ max following conditioning was due only to conditioning. Because the rate of recovery work was increased in the exercise group (because $\mathrm{VO}_{2}$ max increased) but not in the control group, the increased lactate disappearance rate observed may have only been due to the increased recovery intensity. Previous studies have shown that the rate of blood lactate disappearance increases with increased intensity of active recovery up to approximately $40 \% \mathrm{VO}_{2} \max$ (Belcastro and Bonen, 1975; Davies et al, 1970; Hermansen and
Stensvold, 1972). The results for passive recovery and for active recovery at a constant work rate are more clearly interpretable.

Other studies have also observed higher rates of blood lactate disappearance during active recovery from exercise by well-conditioned individuals compared with individuals less well-conditioned, when the more highlyconditioned person was performing recovery work at a higher absolute intensity (Bonen and Belcastro, 1976; Davies et al, 1970; Gisolfi et al, 1966; Strom, 1949). It is not clear, however, whether the higher observed disappearance rates in those studies occurred because the recovery intensity was higher or because the individuals were more highly conditioned. In theory, the peak rate of blood lactate disappearance should occur just below the anaerobic threshold (Stamford et al, 1981). Because the anaerobic threshold occurs at a higher $\% \mathrm{VO}_{2} \max$ in trained individuals (Davies et al, 1979; Williams et al, 1967), the peak rate of blood lactate disappearance should occur at both a higher relative and absolute $\mathrm{VO}_{2}$ in trained compared to untrained individuals. A study of the effect of conditioning on the peak rate of blood lactate removal is clearly needed.

In conclusion, the findings of this study indicate that physical conditioning does not affect the rate of disappearance of lactate from the blood during passive recovery or during active recovery at a given absolute intensity that is considerably below the anaerobic threshold. Additional research is needed to investigate the effect of conditioning on the rate of blood lactate disappearance at various percentages of $\mathrm{VO}_{2}$ max, above and below the anaerobic threshold, including the peak disappearance rate.

Reprint requests to Dr. Blanche Evans, Coleman Gymnasium, University of North Carolina at Greensboro, Greensboro, North Carolina 27412, USA.

\section{REFERENCES}

Barker, S. D. and Summerson, W. D., 1941 "The colorimetric determination of lactic acid in biological material". J.Biol.Chem. 138: 535-554.

Belcastro, A. N. and Bonen, A., 1975 "Lactic acid removal rates during controlled and uncontrolled recovery exercise". J.Appl.Physiol. 39: 932-935.

Bonen, A. and Belcastro, A. N., 1976 "Comparison of self-selected recovery methods on lactic acid removal rates". Med.Sci.Sports 8: 176-178.

Bonen, A., Campbell, C. J., Kirby, R. L. and Belcastro, A. N., 1978 "Relationship between slow-twitch muscle fibers and lactic acid removal". Can.J.Appl.Sport Sci. 3: 160-162.

Clausen, J. P. and Trap-Jensen, J., 1972 “Effects of training on the distribution of cardiac output in patients with coronary artery disease". Circulation 42: 611-624. 
Davies, C. T. M., Knibbs, A. V. and Musgrove, J., 1970 "The rate of lactic acid removal in relation to different baselines of recovery exercise". Eur.J.Appl.Physiol. 28: 155-161.

Davis, J. A., Frank, M. H., Whipp, B. J. and Wasserman, K., 1979 "Anaerobic threshold alterations caused by endurance training in middle-aged men". J.Appl.Physiol. 46: 1039-1046.

Gisolfi, C., Robinson, S. and Turrell, E. S., 1966 "Effects of aerobic work performed during recovery from exhausting work". J.Appl.Physiol. 21: 1767-1772.

Gollnick, P. and Hermansen, L., 1973 "Biochemical adaptations to exercise: anaerobic metabolism". In: Wilmore, J. H. (ed.), Exercise and Sport Sciences Reviews, Vol. 1. Academic Press, New York, pp. 1-43.

Hermansen, L. and Stensvold, I., 1972 "Production and removal of lactate during exercise in man". Acta Physiol. Scand. 86: 191-201.

Holloszy, J. O., Rennie, M. J., Hickson, R. C., Conlee, R. K. and Hagberg, J. M., 1977 "Physiological consequences of the biochemical adaptations to endurance exercise". Ann.N.Y.Acad.Sci. 301: 440-450.

Johnson, R. E. and Brouha, L., 1942 "Pulse rate, blood lactate, and duration of effort in relation to ability to perform strenuous exercise". Rev.Can.Biol. 1: 171-178.

Margaria, R., Edwards, H. T. and Dill, D. B., 1933 "The possible mechanisms of contracting and paying the oxygen debt and the role of lactic acid in muscular contration". Am.J.Physiol. 106: 689-715.

Newman, E. V., Dill, D. B., Edwards, H. T. and Webster, F. A., 1937 "The rate of lactice acid removal in exercise". Am.J.Physiol. 118: 457-461.

Rammal, K. and Strom, G., 1949 "The rate of lactate utilization in man during work and at rest". Acta Physiol.Scand. 17: 452-456.

Robinson, S. and Harmon, R. M., 1941 "The lactic acid mechanism and certain properties of the blood in relation to training". Am.J.Physiol. 132: 757-769.

Stamford, B. A., Rowland, R. and Moffatt, R. J., 1978 "Effects of severe prior exercise on assessment of maximal oxygen uptake". J.Appl.Physiol. 44: 559-563.

Stamford, B. A., Weltman, A., Moffatt, R. and Sady, S., 1981 "Exercise recovery above and below anaerobic threshold following maximal work". J.Appl.Physiol. 51 : 840-844.

Strom, G., 1949 "The influence of anoxia on lactate utilization in man after prolonged muscular work". Acta Physiol. Scand. 17: 440-451.

Vanauskas, E., Bjorntorp, P., Fohlen, M., Pierovsky, I. and Stenberg, J., 1970 “Effects of physical training on exercise blood flow and enzymatic activity in skeletal muscle". Cardiovasc. Res. 4: 418-422.

Weltman, A., Stamford, B. A., Moffatt, R. J. and Katch, V. L., 1977 "Exercise recovery, lactate removal, and subsequent high intensity exercise performance". Res. Q. 48: 786-796.

Weltman, A., Stamford, B. A. and Fulco, C., 1979 "Recovery from maximal effort exercise: lactate disappearance and subsequent performance". J.Appl.Physiol. 47: 677-682.

Williams, C. G., Wyndham, C. H., Kok, R. and von Rahden, M. J. E., 1967 "Effect of training on maximum oxygen intake and on anaerobic metabolism in man". Eur.J.Appl.Physiol. 24: 18-23.

Wilmore, J. H. and Costill, D. L., 1974 "Semi-automated systems approach to the assessment of oxygen uptake during exercise". J.Appl.Physiol. 36: 618-620. 